\title{
LEGAL PRINCIPLES OF THE SCIENTIFIC AND TECHNOLOGICAL INTEGRATION OF THE EAEU MEMBER STATES: CONCEPTUAL ANALYSIS ${ }^{1}$
}

\author{
Mark V. Shugurov \\ Saratov State Law Academy, Saratov, Russian Federation
}

\begin{abstract}
Introduction: in the context of the implementation of the declared technological modernization of the EAEU economy, the issue of developing the legal framework for the integration in the field of science, technology and innovation, and especially the issue of developing a system of its legal principles, is being updated. The purpose of the study is to develop a comprehensive conceptual understanding of the nature, system and functions of the legal principles that are the core of the legal regulation of the integration cooperation of the EAEU member states in the field of science, technology and innovation. The objectives of the study are the following: 1) to relate the legal principles of the regulation of scientific and technological integration with the principles of the Eurasian integration in general; 2) to carry out a consistent analysis of the degree of consolidation of the principles of scientific and technological integration in Union law; 3) to carry out the doctrinal classification of the principles. Methods: general scientific methods (system, structural and functional), specific scientific methods (comparative legal, dogmatic legal). Results: a classification of the legal principles of scientific and technological integration is proposed, the system of which includes a subgroup of general principles, as well as a subgroup of industry (structural-institutional, integration-legal and organizational) principles. Conclusions: the systematized legal principles are conceptualized as the key legal tools for managing integration processes in the field of science, technology and innovation, the formal consolidation of which will serve as a factor for expanding and deepening the regional scientific and technological integration of the member states.

Key words: the Eurasian Economic Union, scientific and technological integration, Union law, integration processes, legal principles, digital transformation, technological modernization.

Citation. Shugurov M.V. Legal Principles of the Scientific and Technological Integration of the EAEU Member States: Conceptual Analysis. Legal Concept = Pravovaya paradigma, 2020, vol. 19, no. 4, pp. 24-32. (in Russian). DOI: https://doi.org/10.15688/lc.jvolsu.2020.4.3
\end{abstract}

УДК 341.2

Дата поступления статьи: 11.09 .2020

ББК 67.91

Дата принятия статьи: 01.10.2020

\section{ПРАВОВЫЕ ПРИНЦИПЫ НАУЧНО-ТЕХНОЛОГИЧЕСКОЙ ИНТЕГРАЦИИ ГОСУДАРСТВ - ЧЛЕНОВ ЕАЭС: КОНЦЕПТУАЛЬНЫЙ АНАЛИЗ ${ }^{1}$}

\author{
Марк Владимирович Шугуров \\ Саратовская государственная юридическая академия, г. Саратов, Российская Федерация
}

\begin{abstract}
Введение: в условиях реализации заявленной технологической модернизации экономики ЕАЭС актуализируется вопрос о развитии правовой базы интеграции в сфере науки, технологий и инноваций, а особенно вопрос о разработке системы ее правовых принципов. Цель исследования заключается в выработке комплексного концептуального представления о природе, системе и функциях правовых принципов, являющ. щихся ядром правового регулирования интеграционного сотрудничества государств - членов ЕАЭС в сфере ๓̊ науки, технологий и инноваций. Задачи исследования: 1) установить связь правовых принципов регулирован ния научно-технологической интеграции с принципами евразийской интеграции в целом; 2) осуществить последовательный анализ степени закрепления принципов научно-технологической интеграции в праве Союза; 3) осуществить доктринальную классификацию рассматриваемых принципов. Методы: общенаучные (системный, структурно-функциональный) и частнонаучные (сравнительно-правовой, догматическо-правовой) методы. Результаты: предложена классификация правовых принципов научно-технологической ин-
\end{abstract}


теграции, система которых включает подгруппу общих, а также подгруппу отраслевых (структурно-институциональных, интеграционно-правовых и организационных) принципов. Выводы: систематизированные правовые принципы концептуализированы в качестве ключевых правовых инструментов управления интеграционными процессами в сфере науки, технологий и инноваций, формальное закрепление которых выступит фактором расширения и углубления региональной научно-технологической интеграции государств членов.

Ключевые слова: Евразийский экономический союз, научно-технологическая интеграция, право Союза, интеграционные процессы, правовые принципы, цифровые трансформации, технологическая модернизация.

Цитирование. Шугуров М. В. Правовые принципы научно-технологической интеграции государств членов ЕАЭС: концептуальный анализ // Legal Concept $=$ Правовая парадигма. -2020 . - Т. 19, № 4. - C. 24-32. DOI: https://doi.org/10.15688/lc.jvolsu.2020.4.3

\section{Введение}

В условиях перехода к Четвертой промышленной революции, характеризующейся новыми технологиями производственного процесса, актуализируется потребность в ускорении и расширении интеграции государствчленов ЕАЭС в сфере науки, технологий и инноваций. В разделе 2 Декларации о дальнейшем развитии интеграционных процессов, посвященном вопросам формирования территории инноваций и обеспечения технологических прорывов [4], взаимодействие в сфере науки, технологий и инноваций выделено в самостоятельное интеграционное направление. Это придает импульс для формирования целостного правового комплекса в рамках права Союза, призванного стать регуляторной основой интеграционных процессов в научнотехнологической и инновационной сфере.

Проблематика формирования и развития данного правового комплекса начинает входить в пространство внимания исследователей $[6 ; 14]$. Однако не будем забывать, что ядром правового регулирования интеграционных процессов в сфере науки, технологий и инноваций, конечно же, выступают правовые принципы. Следует согласиться со сформулированной в научной литературе точкой зрения о том, что изучение единого правового пространства в рамках ЕАЭС предполагает исследование не только структуры права Союза, но и выделение его принципов, являющихся базовыми основами евразийской интеграции [9]. К сожалению, проблематика принципов правового регулирования научно-технологической интеграции государств - членов ЕАЭС пока что не нашла своего освещения в науч- ной литературе. В связи с этим целью представленной статьи является концептуальное осмысление природы, системы и функций принципов, выступающих фундаментальным средством правового регулирования интеграционного сотрудничества в сфере науки, технологий и инноваций.

\section{Основная часть}

Как следует из ст. 4 Договора о ЕАЭС, в качестве одной из целей функционирования Союза выступает модернизация национальных экономик государств - членов [5]. Вполне аксиоматично, что отмеченная модернизация предполагает новую технологическую базу. В связи с этим в ряде разделов Договора предусматривается развитие научно-технологического сотрудничества государств - членов в сфере промышленности, АПК и транспорта при координирующей роли Евразийской экономической комиссии (далее - ЕЭК). В развитие положений Договора принят целый ряд актов институциональных органов ЕАЭС, имеющих рекомендательный характер [13]. Однако в силу того, что в ЕАЭС пока нет специальных международных договоров по вопросам научно-технологического сотрудничества, договорное закрепление интересующих нас принципов отсутствует. Нельзя не констатировать также отсутствие их закрепления в актах институциональных органов Союза, а также в документах программно-стратегического характера.

Следует пояснить, что, поскольку ключевой основой международного научно-технологического сотрудничества и развития, а также его конкретных организационных форм 
выступают принципы, формальное закрепление последних является в целом широко распространенной практикой двусторонних и многосторонних договоров государств в научно-технической сфере. Это связано с тем, что принципы являются своего рода первичной основой возникновения базовых международно-правовых обязательств, которые, в свою очередь, задают содержательные рамки обязательств, возникающих на основе положений о взаимодействии Сторон в рамках тех или иных организационно-правовых форм научно-технологического сотрудничества (обмен специалистами, совместные разработки, передача технологий, обмен научной информацией и т. д.). Из сказанного следует, что концептуализация принципов имеет не только теоретическую, но и практическую актуальность.

Это связано с тем, что в настоящий момент ясно осознается значимость развития правовой базы ЕАЭС в научно-технологической сфере, и особенно базы договорной [16]. Причем, как нам представляется, право Союза в сфере научно-технологического взаимодействия должно не только предусматривать современные и перспективные формы сотрудничества, но и закреплять его принципы. Казалось бы, формулировка правовых принципов не представляет особой проблемы. Однако это не так, ибо системное научно-технологическое взаимодействие в ЕАЭС находится в начальной стадии своего формирования. В связи с этим именно от системы установленных правовых принципов во многом будет зависеть глобальная научно-технологическая конкурентоспособность Союза.

Как таковые, правовые принципы международного научно-технологического сотрудничества являются универсальными, то есть «пронизывающими» все его формы, а именно - конкуренцию, координацию, коллаборацию, кооперацию, интеграцию [10, с. 20-26]. В литературе выделяют и иные перечни форм научно-технологического сотрудничества, в которые включаются, например, ассоциация, гармонизация и т. д. Но не следует забывать, что научно-технологическое сотрудничество в рамках ЕАЭС разворачивается внутри интеграционного объединения государств. В результате научно-технологическая интеграция представляет собой приоритетную форму сотрудничества, тогда как приоритетом научнотехнологического сотрудничества на двусторонней международно-договорной основе является все же кооперация. Правовой основой последней, например, выступают двусторонние договоры, заключенные государствами - членами ЕАЭС, но в право Союза они не входят.

Представляется, что природа рассматриваемых принципов коррелятивна природе принципов интеграционного взаимодействия, выступающих фундаментальными ориентирами, закрепляющими евразийскую модель интеграции. Здесь необходимо внести уточнение, касающееся того, что, во-первых, участие в Союзе открывает для каждого государства новые возможности для решения задач национального развития - не только экономических, но и технологических, а также научно-образовательных - на основе получения общего синергетического эффекта от интеграции. Во-вторых, участие в Союзе основано на незыблемом соблюдении национальных интересов и уважении государственного суверенитета. В основных чертах налицо международно-правовая, а не наднационально-правовая модель интеграции. Однако в литературе признается, что правовая модель евразийской интеграции является смешанной, то есть включающей в себя некоторые компоненты наднациональности [12, с. 79]. Конечно, здесь возникает вопрос о том, насколько выбранная модель интеграции и соответствующая ей сущностная модель правовых принципов адекватна потребностям дальнейшего углубления интеграции.

Очевидно, что данная модель определяет идентичность Союза, но представляется вполне возможным в дальнейшем усилить наднациональный компонент. В нашем случае это означало бы расширение полномочий ЕЭК, что позволило бы ей более интенсивно и масштабно осуществлять координирующую функцию в сфере научно-технологического сотрудничества. В результате развития такого сценария возникнет возможность развития системы принципов региональной научно-технологической интеграции. Однако первоначально должно быть сформировано комплексное концептуальное представление о них, а 
также должно быть осуществлено их формальное закрепление в правовой базе Союза.

Казалось бы, интересующие нас принципы в силу международно-правовой модели евразийской интеграции на уровне Союза сходны с принципами, характерными для договорной (конвенционной) модели научно-технологического сотрудничества, реализующейся на двустороннем или же на многостороннем уровне. Но в нашем случае налицо не просто региональный уровень международно-правового сотрудничества в сфере науки, технологий и инноваций, но сотрудничество в рамках международной организации региональной экономической интеграции. Соответственно, здесь система принципов не может по своему определению полностью совпадать с системой правовых принципов научно-технологического сотрудничества в рамках, например, такого межгосударственного объединения, как ШОС, которые в последнее время подверглись в доктрине серьезному анализу [1].

Соответственно, система правовых принципов научно-технологического сотрудничества всякий раз представляет собой достаточно уникальный комплекс, характерный для разных видов межгосударственных объединений, включая те или иные интеграционные образования государств. Это не означает отсутствия инвариантного ядра, аналогичного ядру принципов, характерных для многостороннего научно-технологического сотрудничества, осуществляющегося на универсальном уровне в рамках международных договоров, сторонами которых выступает подавляющее число государств современного мира (Конвенция $\mathrm{OOH}$ о биоразнообразии, Рамочная конвенция ООН об изменении климата, Минаматская конвенция по ртути и т. д.). В целом к общим относятся принципы добровольности, равноправия, недискриминации, добросовестного исполнения международно-правовых обязательств по научно-технологическому сотрудничеству, сближение уровней экономического и научно-технологического развития между развитыми и развивающимися странами, взаимной выгоды и справедливого распределения выгод от достигнутых результатов совместной научно-исследовательской деятельности в рамках международного сотрудничества, свободы научных исследований, обме- на информацией и результатами научных исследований, принцип конфиденциальности [2, c. 184]. В свою очередь, на уровне региональных объединений государств в рамках договорного и программного сотрудничества более выраженной оказывается именно подсистема специальных принципов.

По замечанию Л.П. Ануфриевой, принципы, будучи руководящими нормами, органично связаны со всеми составляющими научно-технологического сотрудничества, а именно «спецификой объекта регулирования (видом общественных отношений), предметом юридического воздействия, формами реализации сотрудничества, субъектами и др.» [2, с. 184]. С данным подходом всецело следует согласиться, но его можно дополнить концептуальным положением о том, что важнейшим фактором детерминации правовых принципов научно-технологического сотрудничества на уровне интеграционных объединений государств является система принципов, на которых строит свою деятельность то или иное межгосударственное объединение как таковое.

Так, одни исследователи выделяют принцииы права ЕАЭС, в частности общие (охрана прав и свобод граждан государств членов ЕАЭС; правовая определенность; субсидиарность и пропорциональность; недискриминация) и функциональные (верховенство права ЕАЭС; интегрированность права ЕАЭС в национальные правовые системы), пронизывающие все сферы интеграционного взаимодействия [9]. Другие авторы говорят о принципах функционирования ЕАЭС и классифицируют их как общие (международные); структурно-институциональные, задающие основы функционирования институтов ЕАЭС; и, наконец, принципы правовой интеграции, регулирующие отношения между государствами - членами в процессе интеграционного взаимодействия. Одновременно делается вывод о том, что отраслевые принципы, так же, как и межотраслевые, требуют своего специального анализа [7, с. 89]. И, наконец, третий подход заключается в выделении принщипов евразийской интеграции: институциональные (соблюдение норм международного права, равноправие сторон, добровольность, суверенность), организационные (открытый характер, 
транспарентность, гибкость интеграции, общественный консенсус), социально-экономические (экономический прагматизм, рыночный интеграционизм, добросовестная конкуренция и др.) [15, с. 175]. На наш взгляд, более продуманным является второй подход, ибо он наиболее полно отражает правовой алгоритм евразийской интеграции. В результате отмеченный плюрализм подходов в сфере доктринальной систематизации принципов интеграционного взаимодействия в рамках ЕАЭС не столько создает определенные трудности для моделирования системы отраслевых принципов, к которым относятся принципы правового регулирования научно-технологической интеграции в рамках ЕАЭС, сколько служит исходной предпосылкой их классификации.

С нашей точки зрения, вполне целесообразно объединить структурно-институциональные принципы и принципы правовой интеграции в качестве самостоятельных подгрупп в составе подсистемы специальных принципов. Эвристичность выбранного нами подхода в качестве исходной методологической основы можно продемонстрировать на примере имеющегося закрепления отраслевых принципов. Например, в силу актуальности такого интеграционного направления, как цифровые трансформации экономики и общества, следует указать на принципы реализации цифровой повестки Союза. Так, реализация цифровой повестки ЕАЭС, как это закреплено в «Основных направлениях реализации Цифровой повестки Евразийского экономического союза до 2025 г.», призвана способствовать открытому, широкому и равноправному сотрудничеству государств - членов, их хозяйствующих субъектов и граждан, росту эффективности и объемов экономики каждого из государств - членов, переходу на новый уровень экономического, технологического и социального развития, а также укреплению роли государств - членов и Союза в формировании глобальной цифровой повестки [11]. Далее в этом документе выделен специальный блок принципов: равноправное партнерство; развитие интеграции и сотрудничества государств - членов в ходе реализации цифровой повестки; синергия в процессе решения государствами - членами совместных задач в рамках Союза; расширение включенности в цифровую повестку и преодоление всех форм цифрового неравенства и др. Представляется, что указанный перечень включает принципы общего и специального характера. В свою очередь, среди специальных в нем можно выделить институциональные принципы (обоснованность актов, принимаемых Союзом) и принципы интеграционного взаимодействия (сопряжение национальных информационных систем государств - членов). Специальный блок, посвященный принципам, можно также увидеть в Концепции создания условий для цифровой трансформации промышленного сотрудничества в рамках ЕАЭС и цифровой трансформации промышленности государств Союза [8]. Так, в разделе III выделены следующие принципы цифровой трансформации: системность при разработке и координации процессов цифровой трансформации промышленного сотрудничества и цифровой трансформации промышленности; руководящая роль государственных органов в партнерстве с бизнес-сообществами государств членов; использование механизмов государственно-частного партнерства при реализации проектов по цифровой трансформации промышленности и др. Как можно видеть, здесь отражены преимущественно специальные отраслевые принципы.

Система принципов в сфере научно-технологического взаимодействия и основа их классификации имеет самостоятельный теоретический интерес. Это объясняется тем, что право ЕАЭС в рассматриваемой сфере еще достаточно фрагментарно, что своей конечной причиной имеет недостаточную интенсивность кооперационных связей, отсутствие общих проектов и отсутствие общей инфраструктуры. Как бы то ни было, формирование целостной правовой базы научно-технологической интеграции предполагает формирование целостной системы принципов. Бесспорно, наиболее полную систематизацию они могут и должны получить на уровне доктрины, что станет важной научно-теоретической основой их закрепления в различных международно-правовых договорах в научно-технической сфере, если, конечно, государства - члены ЕАЭС посчитают, что их принятие является необходимым. Таким образом, доктринальная систематизация принципов в настоящее время представля- 
М.В. Шугуров. Правовые принципы научно-технологической интеграции государств - членов ЕАЭС

ет собой не результат обобщения и интерпретации формально закрепленных принципов, а творческое конструирование их системы.

Ввиду выбранного нами подхода, предполагающего деление системы принципов правового регулирования научно-технологического сотрудничества на общие и специальные при одновременном учете специфики интеграционного характера научно-технологического взаимодействия государств, мы будем следовать данной схеме. Одновременно отметим, что существенным методологическим моментом представляется признание открытого характера перечней, относящихся к той или иной их подсистеме.

К подсистеме общих принципов правового регулирования отношений государств членов ЕАЭС следует отнести принцип сотрудничества, который задает наиболее общее обязательство по решению проблемы укрепления национальных научно-технологических потенциалов государств - членов на совместной основе. Данный принцип находит свое дополнение в принципе суверенного равенства государств - членов в процессе осуществления научно-технологического сотрудничества. Его значение можно обосновать тем, что в ЕАЭС сформирован уникальный механизм реализации национального суверенитета в рамках Союза. Не менее важным является принцип взаимной выгоды, который можно рассматривать как конкретизацию принципа сотрудничества именно как взаимовыгодного сотрудничества. В частности, в отношении формирования общего научно-образовательного пространства делаются выводы о том, что «выгоды для участников интеграционного объединения ЕАЭС в настоящее время распределяются неравномерно. Это связано как с неоднородностью самого пространства, так и с местом каждого субъекта в нем. Выгоды в дальнейшем будут зависеть от развитости создаваемых институтов» [3, c. 18]. Отсюда возникает потребность в меpax, которые привели бы к балансу интересов. В связи с этим вполне понятно, что интеграция как взаимодействие на основе специальных механизмов должна быть нацелена на наиболее полную реализацию данного принципа, что вполне коррелирует принципу суверенного равенства государств, который в процессе его реализации должен подвести к равенству не только возможностей, но и результата.

Не менее важную и может быть более интересную подсистему представляет собой группа специальных принципов, которые являются основой для возникновения обязательств по формированию и запуску конкретных механизмов интеграции. Принципом структурноинституционального характера является принцип координирующей функции ЕЭК, который закреплен не только в Договоре о ЕАЭС, но и в документах институциональных органов. По мере развития и углубления научно-технологической интеграции объем ее функций будет неуклонного возрастать. В свою очередь, принципы правовой интеграции представлены требованиями по осуществлению, во-первых, координации и согласования правовой политики государств - членов в сфере науки, технологий и инноваций, а во-вторых, содействия развитию и функционированию проектной основы научно-технологической интеграции. На формирование и реализацию совместных высокотехнологических проектов указывается в Декларации о дальнейшем развитии интеграционных процессов. Все это вполне коррелирует проектному подходу реализации Цифровой повестки Союза. И, наконец, нельзя не отметить принцип сочетания и взаимодополнения интеграции в секторе НИОКР и коммерциализации технологических разработок интеграцией в сфере фундаментальных исследований. В силу необходимости достижения зримого результата научно-технологической интеграции, от успехов которой во многом зависит достижение целей Союза, мы бы включили в рассматриваемую подсистему принцип координации и согласования национальных научно-технологических политик и гармонизации соответствующего законодательства.

Выделим подгруппу принципов организационного характера. В их число входит принцип использования механизмов государственночастного партнерства, что позволит создать условия для вовлечения в научно-технологическое сотрудничество как можно большего круга заинтересованных субъектов. Не менее важным является принцип кросс-отраслевой научно-технологической интеграции, что вполне соответствует тенденции расширения ис- 
пользования конвергентных технологий и сопряжения сфер научно-технологического сотрудничества. Укажем также на принцип развития сетевых цифровых структур и платформ научно-технологического сотрудничества. Он является преломлением тенденции цифровых трансформаций научно-технологических комплексов и инфраструктуры. И, наконец, укажем на принцип свободы выбора организации научных и научно-технологических связей.

Моделирование композиционной архитектоники различных видовых принципов предполагает, что они выполняют только им присущие видовые функции. В случае с общими принципами это функция поддержания основополагающих рамок реализации идеи евразийской научно-технологической интеграции. Во втором случае, а именно в специальных принципах, можно видеть регуляторный вектор, ориентирующий на решение ключевых вопросов практического взаимодействия в сфере совместных разработок и коммерциализации технологий. При этом как в отношении общих, так и в отношении специальных принципов одинаково верным представляется то, что они являются рамками для разработки нормативной правовой базы ЕАЭС в сфере научно-технологической интеграции и одновременно - действенными регулирующими началами, играющими важную роль в условиях существования имеющихся на сегодняшний день правовых пробелов.

\section{Заключение}

Подводя итоги проведенного исследования, сформулируем ряд выводов. Во-первых, систематизированные нами принципы в широком смысле следует понимать в качестве ключевых правовых инструментов управления интеграционными процессами в сфере науки, технологий и инноваций. Во-вторых, по мере развития процессов научно-технологической интеграции возникнут предпосылки для развития их содержания в доктринальном аспекте, что будет сопровождаться процессом их уточнения, а также дальнейшим дополнением их системы новыми специальными принципами. В-третьих, следует констатировать необходимость проведения исследований по осуществлению сравнения правовых принципов научно-технологи- ческого сотрудничества в рамках тех или иных интеграционных объединений государств, что позволит осмыслить правовые принципы, характерные для ЕАЭС, с точки зрения категорий «общее - особенное».

\section{ПРИМЕЧАНИЕ}

${ }^{1}$ Исследование выполнено при финансовой поддержке РФФИ в рамках научного проекта № 20011-00780 «Модель правового регулирования научно-технологической и инновационной интеграции в рамках ЕАЭС и вызовы Четвертой промышленной революции».

The work was supported by RFBR in the framework of scientific project no. 20-011-00780 "Model of legal regulation of scientific, technological and innovative integration within the EAEU and challenges of the Fourth Industrial Revolution".

\section{СПИСОК ЛИТЕРАТУРЫ}

1. Аничкин, Е. С. Система правовых принципов международного и научно-технического сотрудничества в Шанхайской организации сотрудничества / Е. С. Аничкин, А. А. Серебряков // Алтайский юридический вестник. - 2019. - № 2. - С. 13-19.

2. Ануфриева, Л. П. Принципы и правовые формы сотрудничества в области науки, техники и инноваций между Россией и странами ЕС / Л. П. Ануфриева // Актуальные проблемы российского права. - 2018. - № 12. - С. 175-186.

3. Базарбаева, Р. Ш. Научно-образовательное сотрудничество университетов стран ЕАЭС: проблемы и перспективы / Р. Ш. Базарбаева // Вестник экономики, права и социологии. - 2019. - Т. 2, № 3. C. 16-19.

4. Декларация о дальнейшем развитии интеграционных процессов в рамках Евразийского экономического союза 2018 г. (Санкт-Петербург, 6 декабря 2018 г.). - Электрон. текстовые дан. - Режим доступа: https://docs.eaeunion.org/docs/ru-ru/01420213 (дата обращения: 15.05.2020). - Загл. с экрана.

5. Договор о Евразийском экономическом союзе (Астана, 29 мая 2014 г.) (ред. от 15.03.2018 г.). Доступ из справ.-правовой системы «КонсультантПлюс».

6. Дьяконова, А. А. Правовое регулирование научно-технического сотрудничества в условиях современной региональной интеграции: опыт Республики Казахстан / А. А. Дьяконова, О. В. Рахматуллина // Право и государство: теория и практика. 2019. - № 10. - C. 134-136. 
7. Кириленко, В. П. Принципы функционирования Евразийского экономического союза (международно-правовые аспекты) / В. П. Кириленко, Д. Г. Демидов // Управленческое консультирование. -2015 . - № 3 (75), - С. 83-89.

8. Концепция создания условий для цифровой трансформации промышленного сотрудничества в рамках ЕАЭС и цифровой трансформации промышленности государств - членов Союза. - Электрон. текстовые дан. - Режим доступа: http:// www.eursiancommission.org/ru/act/prom_i_agroprom/ dep_prom/SiteAssets/Proekt_Koncepciya_cifra.pdf (дата обращения: 20.08.2020). -Загл. с экрана.

9. Малый, А. Ф. Принципы права Евразийского экономического союза / А. Ф. Малый, О. Ю. Кондрашова // Электронный научный журнал «Наука. Общество. Государство». - 2019. - Т. 7, № 2 (26). Электрон. текстовые дан. - Режим доступа: http:// esj.pnzgu.ru (дата обращения: 20.08.2020). - Загл. с экрана.

10. Нечаева, Е. К. Правовое регулирование научных исследований и технологического развития в рамках региональных интеграционных организаций (на примере Европейского Союза и Евразийского экономического союза) : автореф. дис. ... канд. юрид. наук / Нечаева Елена Константиновна. - М., 2017. $-33 \mathrm{c}$.

11. Основные направления реализации цифровой повестки Евразийского экономического союза до 2025 г. (утверждены Решением Высшего Евразийского экономического совета от 11 октября 2017 № 12). - Доступ из информ.-правового портала «Гарант.ру».

12. Пименова, О. И. Правовая интеграция в Европейском союзе и Евразийском экономическом союзе: сравнительный анализ / О. И. Пименова // Вестник международных организаций. 2019. - № 1. - С. 76-93.

13. Приложение к Рекомендации Комиссии ЕЭК от 28 февраля 2017 № 5 «Перечень приоритетных направлений сотрудничества государств - членов ЕАЭС в целях ускорения технологической модернизации и повышения инновационной активности организаций государств - членов с учетом прикладных и фундаментальных исследований, проводимых государствами - членами». - Электрон. текстовые дан. Режим доступа: https://docs.eaeunion.org/docs/ru-ru/ 01417291/clcr_02032017_5 (дата обращения: 04.09.2020). - Загл. с экрана.

14. Салиева, Р. Н. Правовые основы научно-технического сотрудничеств государств Евразийского экономического союза / Р. Н. Салиева // Вестник экономики, права и социологии. - 2019. - Т. 2, № 3. С. $144-147$.

15. Хапилин, С. А. Теоретико-методологические аспекты исследования принципов евразийской интеграции / С. А. Хапилин // Финансовые исследования. -2015 . - № 2 (47). - С. 173-181.

16. Четвериков, А. О. Организационно-правовые формы Большой науки (мегасайенс) в условиях международной интеграции: сравнительное исследование / А. О. Четвериков // Юридическая наука. - 2018. - № 2 (ч. 2). - С. 34-50.

\section{REFERENCES}

1. Anichkin E.S., Serebryakov A.A. Sistema pravovyh principov mezhdunarodnogo i nauchnotekhnicheskogo sotrudnichestva v Shanhajskoj organizacii sotrudnichestva [The System of Law Principles of International Scientific and ScientificTechnical Cooperation in the Shanghai Cooperation organization]. Altajskij yuridicheskij vestnik [Altai Juridical Bulletin], 2019, no. 2, pp. 13-19.

2. Anufrieva L.P. Principy i pravovye formy sotrudnichestva v oblasti nauki, tekhniki i innovacij mezhdu Rossiej i stranami ES [Principles and Legal Forms of Cooperation in Science, Technology and Innovation Between Russia and the EU Countries]. Aktual'nye problemy rossijskogo prava [Actual Problems of Russian Law], 2018, no. 12, pp. 175-186.

3. Bazarbaeva R.Sh. Nauchno-obrazovatel'noe sotrudnichestvo universitetov stran EAES: problemy i perspektivy [Scientific and Educational Cooperation of Universities of the EAEU Countries]. Vestnik ekonomiki, prava i sociologii [The Review of Economy, the Law and Sociology], 2019, no. 3, vol. 2, pp. 16-19.

4. Deklaraciya o dal'nejshem razvitii integracionnyh processov v ramkah Evrazijskogo ekonomicheskogo soyuza 2018 g. (Sankt-Peterburg, 6 dekabrya 2018 g.) [Declaration of the Further Development of Integrative Processes Within the Framework of the Eurasian Economic Union]. URL: https://docs.eaeunion.org/docs/ru-ru/01420213/ (accessed 15 May 2020).

5. Dogovor o Evrazijskom ekonomicheskom soyuze (Astana, 29 maya 2014 g.) (red. ot 15.03.2018 g.) [The Treaty on Eurasian Economic Union]. Access from Reference Legal System 'KonsultantPlyus'.

6. D’yakonova A.A., Rahmatullina O.V. Pravovoe regulirovanie nauchno-tekhnicheskogo sotrudnichestva v usloviyah sovremennoj regional'noj integracii: opyt Respubliki Kazahstan [Legal Regulation of Scientific and Technical Cooperation in the Condition of Contemporary Regional Integration: Experience of the Republic of Kazakhstan]. Pravo $i$ gosudarstvo teoriia i praktika [Law and State: Theory and Practice], 2019, no. 10, pp. 134-136.

7. Kirilenko V.P., Demidov D.G. Principy funkcionirovaniya Evrazijskogo ekonomicheskogo 
soyuza (mezhdunarodno-pravovye aspekty) [Principles of Functioning of the Eurasian Economic Union (International Legal Aspects]. Upravlencheskoe konsul'tirovanie [Administrative Consulting], 2015, no. 3 (75), pp. 83-89.

8. Koncepciya sozdaniya uslovij dlya cifrovoj transformacii promyshlennogo sotrudnichestva $v$ ramkah EAES i cifrovoj transformacii promyshlennosti gosudarstv - chlenov Soyuza [Concept of Formation Conditions for Transformation of Cooperation in Industry Within the Framework of EAEU and for Digital Transformation of Industry of Member States of the Union]. URL: http://www.eursiancommission.org/ru/ act/prom_i_agroprom/dep_prom/SiteAssets/ Proekt_Koncepciya_cifra.pdf (accessed 20 August 2020).

9. Malyj A.F., Kondrashova O.YU. Principyprava Evrazijskogo eko-nomicheskogo soyuza [Principles of the law of Eurasian Economic Union as a Basis for its Legal System]. Nauka. Obshchestvo. Gosudarstvo [Science. Society. State], 2019, vol. 7, no. 2 (26). URL: http://esj.pnzgu.ru (accessed 20 August 2020).

10. Nechaeva E.K. Pravovoe regulirovanie nauchnyh issledovanij i tekhno-logicheskogo razvitiya $v$ ramkah regional'nyh integracionnyh organizacij (na primere Evropejskogo Soyuza $i$ Evrazijskogo ekonomicheskogo soyuza): avtoref. diss. ... kand. yurid. nauk [Legal Regulation of Scientific Research and Technological Development Within the Framework of Regional Integrative Organizations (On Example of the European Union and the Eurasian Union]. Moscow, 2017. 32 p.

11. Osnovnye napravleniya realizacii cifrovoj povestki Evrazijskogo ekonomicheskogo soyuza do 2025 g. (11 oktyabrya 2017 № 12) [The Main Directions of Development of Realization of the Digital Agenda of Eurasian Economic Union (11 October 2017)]. Access from “Garant” Informational and Legal Web Portal.

12. Pimenova O.I. Pravovaya integraciya $v$ Evropejskom soyuze i Evrazijskom ekonomicheskom soyuze: sravnitel'nyj analiz [Legal Integration in the
European Union and the Eurasian Economic Union: Comparative Analysis]. Vestnik mezhdunarodnyh organizacij [International Organization Research Journal], 2019, no. 1, pp. 76-93.

13. Prilozhenie k Rekomendacii Komissii EEK ot 28 fevralya 2017 № 5 «Perechen' prioritetnyh napravlenij sotrudnichestva gosudarstv-chlenov EAES v celyah uskoreniya tekhnologicheskoj modernizacii i povysheniya innovacionnoj aktivnosti organizacij gosudarstv - chlenov s uchetom prikladnyh $i$ fundamental'nyh issledovanij, provodimyh gosudarstvami-chlenami [Annex to Recommendation of the Eurasian Economic Commission "List of Priority Directions of Cooperation of Member States of EAEU for the Purposes of Accelerating the Technological Modernization and Increasing the Innovation Activity of Organizations of Member States, Taking into Account Applied and Basic Research, Conducted by Member States]. URL: https://docs.eaeunion.org/docs/ru-ru/01417291/ clcr_02032017_5 (accessed 4 September 2020).

14. Salieva R.N. Pravovye osnovy nauchnotekhnicheskogo sotrudnichestv gosudarstv Evrazijskogo ekonomicheskogo soyuza [Legal Foundation of Scientific and Technical Cooperation of States of the Eurasian Economic Union]. Vestnik ekonomiki, prava i sociologii [The Review of Economy, the Law and Sociology], 2019, no. 3, vol. 2, pp. 144-147.

15. Hapilin S.A. Teoretiko-metodologicheskie aspekty issledovaniya principov evrazijskoj integracii [Theoretical Aspects of Research of the Principles of Eurasian Integration]. Finansovye issledovaniya [Financial Studies], 2015, no. 2(47), pp. 173-181.

16. Chetverikov A.O. Organizacionno-pravovye formy bol'shoj nauki (megasajens) v usloviyah mezhdunarodnoj integracii: sravnitel'noe issledovanie (Chast' 2) [Institutional and Legal Forms of Big Science (Megascience) in the Context of International Integration: Comparative Study (Part 2)]. Yuridicheskaya nauka [Legal Science], 2018, no. 2, pp. 34-50.

\section{Information About the Author}

Mark V. Shugurov, Doctor of Sciences (Philosophy), Professor, Department of International Law, Saratov State Law Academy, Volskaya St, 1, 410056 Saratov, Russian Federation, shugurovs@mail.ru, https://orcid.org/0000-003-3604-3961

\section{Информация об авторе}

Марк Владимирович Шугуров, доктор философских наук, профессор кафедры международного права, Саратовская государственная юридическая академия, ул. Вольская, 1, 410056 г. Саратов, Российская Федерация, shugurovs@mail.ru, https://orcid.org/0000-003-3604-3961 